\section{Max Aguirre}

Una arquitectura de la negatividad La modernidad de la arquitectura de las salitreras.

El caso de la Oficina Santa Laura (1872-1960)

El caso de las salitreras en el desierto de Atacama sirve como ejemplo para analizar cómo, con el uso de nuevas tecnologías y una mirada centrada en la actividad productiva y en sus procesos, los asentamientos humanos comienzan a instalarse en enclaves inhóspitos como el extremo norte de Chile. De esta forma, durante el siglo XIX, la oficina salitrera se consolida como pequeño laboratorio de la naciente modernidad.

Palabras clave: Arquitectura - Chile, zonas áridas, salitreras, Revolución Industrial, campamento minero.

The nitrate towns of the Atacama Desert serve as an example for an analysis of how new technologies and a vision focused on productive activities and their processes gave rise to new buman settlements in inhospitable corners of the extreme north of Chile. These $19^{\text {th }}$ century mining communities constituted a miniature laboratory for the birth of modernity.

Key words: Architecture - Chile, arid zones, nitrate mines, ind ustrial revolution, mining camps.
1 La información remitida a notas y las imágenes que ilustran este artículo trabajos realizados por los alumnos en $\mathrm{el}$ Seminario de Investigación $2^{\circ}$ semestre de 1999, Escuela de Arquitectura P.U.C., inédito $\mathrm{s} / \mathrm{p}$, en la sección dirigida por el profesor Max Aguirre G. En cada
caso se ha identificado al alumno desarrolló el trabajo del que se toman los antecedentes. El levantamiento del edificio La Máquina fue ejecutado por los alumnos Francisca Carmona A. Ma. Alejandra Effa R., Braulio Morera V., Carolina Páez, Paul Reid E. y Andre "El área conocida como desierto de tacama (...), $22^{\circ}$ y $26^{\circ}$ de latitud sur poco propicia para el asentamiento (s) agricola (...) (por) la escasez de recursos hidricos, calidad inerte del suelo y condiciones climáticas extremas, las cuales incluyen escasa humedad (1) de ésta (con máximas de $35^{\circ} \mathrm{C}$ en diciembre y minimas de $6^{\circ} \mathrm{C}$ en junio). así como gran luminosidad, con un promedio anual de 38.000 lux, y una altura media sobre le nivel del mar de 200 m" (Garcés, 1999).
"Elconjunto de asentamientos industriales

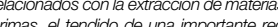
ferroviaria y la construcción de ciudades portuarias, (...) pertenece con propiedad ámbito de la Revolución Industrial (...) que presionó sobre el desarrollo de los paises con (...) modificaciones en lo (...) territorial, Revolución Industrtrial definió marco de la de gestión que se materializó en un (...) territori(o) períférico y extremo, asumiendo una peculiar fisonomía de acuerdo con (... una geografifa signada por el Jíspico a
4 "El desierto de Atacama, (...) empezóa a partir de beneficio de un 1870 natural abundante como es el salitre (Garcés, 1999)
La Oficina Santa Laura ilustra la experiencia de los asentamientos de las oficinas salitreras como avanzada de la arquitectura y el urbanismo de la modernidad.

Uno de los aspectos de mayor impacto de la modernidad arquitectónica fue la capacidad de sobreponerse a las restricciones que imponía el territorio. En ese sentido surgió una arquitectura utópica que, sin encontrar en las condiciones del lugar una restricción insuperable, realizó una obra cuya universalidad la hacía válida para cualquier sitio. La explotación del salitre en Chile, al promediar el siglo XIX, introdujo en el país la experiencia de la producción industrial a gran escala y junto con ella -tempranamenteaplicó en la construcción de sus asentamientos en zonas inhóspitas, las tecnologías y los conceptos propios del urbanismo y arquitectura modernos. Los asentamientos humanos se han caracterizado por aparecer en lugares donde se encuentran condiciones que favorezcan la supervivencia. El valle central donde se fundó Santiago, surcado por los ríos Maipo y Mapocho, y con abundante fauna fue un ejemplo de ello. Esta condición de base era determinante para la ciudad y la arquitectura a que solían dar origen esos asentamientos. La relación entre vida humana, geografía y arquitectura pareció ser por siglos un vínculo ineludible que determinaba la edificación. En esta trilogía lo significativo era el punto de partida dado por la geografía y las condiciones de flora y fauna que asegurarían la pervivencia. Suelos aptos para la agricultura y existencia de aguas sanas fueron dos aspectos esenciales para la elección de un territorio que sostuviera la vida humana.

Bajo esas consideraciones el desierto de Atacama ${ }^{2}$ constituía un territorio con muy bajas condiciones para la vida estable que permitiera el nacimiento de centros urbanos. Pero durante la segunda mitad del siglo XIX irrumpió en Chile la Revolución Industrial, cuando diversas compañías extranjeras, especialmente inglesas, alemanas y estadounidenses, incorporaron al país en la cadena de producción de la Revolución con la explotación masiva del salitre que se hallaba en abundancia en ese desierto ${ }^{3}$. De esta forma, Chile pasó a ser un proveedor de materia prima para la agricultura de los países que lideraban la expansión de los mercados de la que dependía el desarrollo creciente de la industrialización en marcha ${ }^{4}$.

Este hecho ejemplifica el cambio radical que estaba provocando la industrialización, trastornando -en el caso que nos interesa- la relación que parecía
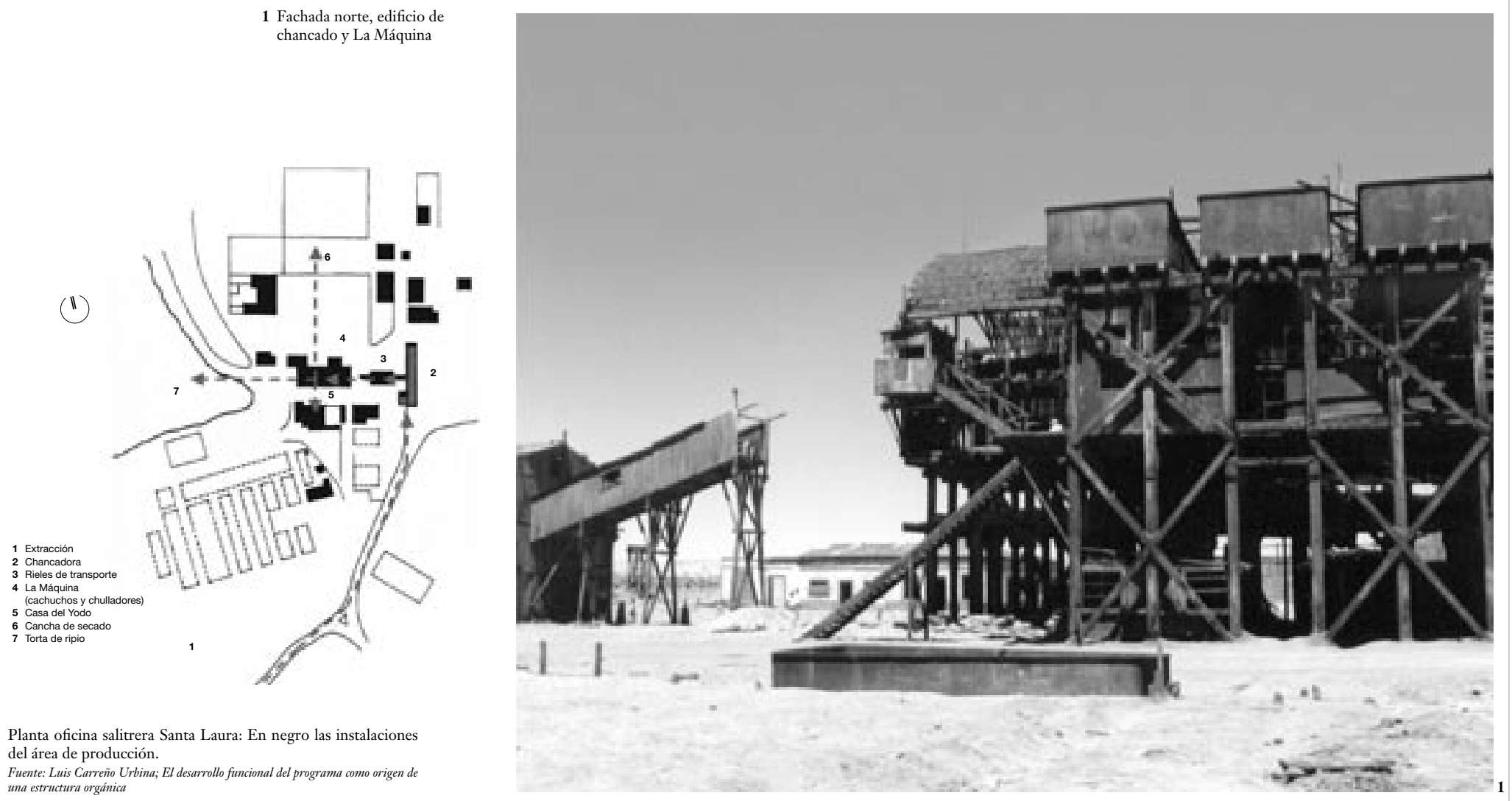
"La actividad salitrera tendió un puente entre el siglo XIX de la Revolución (..).) Aportó a la modernización de Chi y, en particular, hizo una contribución concreta a la construcción del territorio y la formulación dé la ciudad de nueve
fundación" (Garcés, 1999)

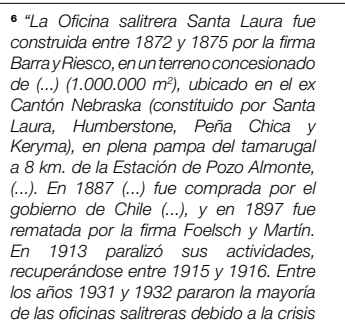

generada por el salitre sintético. Para hacer frente a esta situación, en 1933, se y Antofagasta (COSATAN), que se hizo cargo de las Oficinas y logró prolongar su vida hasta 1960 (....). En 1970 la Oficina Santa Laura fue declarada Monumento Historico Nacional, (...). Actualmente, se postula ante la UNESCO la declaratoria de Carreño U., Luis; El desarrollo funcional del programa como origen de una estructura orgánica. El caso del edificio de chancado de la Officina saltr.
7 "La explotación del salitre y su manejo industrial permitió la ocupación y oficinas salitreras, ferrocariles y puertos. Se construyeron numerosas instalaciones industriales, edificios de equipamiento y vivendas. (...., (en) cerca de 70 oficinas saltireras (...) asociadas a la gestion e internacionales" (Garcés, 1999)

${ }^{8}$ "El proceso proporcionó a la arquitectura chilena un conjunto de obras de notable salitreras. Estos asentamientos fueron (...) organizados en forma autónoma del teritorio (...). La autonomía de los asentamientos fue complementada fundación de puertos hecho ques y la de relieve la ocupación industrial de desierto de Atacama, en la latitud del Trópico de Capricornio" (Garcés, 1999) ineludible entre supervivencia, geografía y arquitectura. La tecnología y el capital al servicio de una producción inmisericorde rompieron la "lógica" que imponía la naturaleza y lograron crear y mantener asentamientos con características urbanas más allá de las limitaciones que la falta de agua y de vegetación, hasta entonces, habían hecho ver insuperables.

A este fenómeno cultural, marcado por la racionalidad científica que sostiene a la tecnología de la producción industrial incentivada por el desarrollo creciente del capital y del mercado, es lo que denominamos modernidad. Constituye, como en el caso que presentaremos a continuación, un cambio de escala en cuanto a la magnitud de los elementos puestos en juego y una modificación de la relación de orden con que se vinculan aspectos de la realidad arquitectónica. Si antes era condición sine qua non la existencia de agua y de vegetación en el lugar para fundar un asentamiento, ahora, la tecnología permitía salvar las carencias del territorio.

En esta perspectiva, la explotación del salitre y las Oficinas asociadas a ella fueron un modelo de ocupación de zonas áridas, inhóspitas, pero, además, en la experiencia de Chile, significó la introducción al país de la modernidad de la producción industrial ${ }^{5} \mathrm{y}$ un precedente del orden arquitectónico moderno que hará su aparición en el país, de la mano de los arquitectos locales, en las primeras décadas del siglo veinte.

La Oficina Santa Laura ${ }^{6}$ fue un ejemplo de ese proceso, la instalación siguió el orden que impuso la producción. Los edificios se situaron en el territorio siguiendo la secuencia de las actividades productivas. La secuencia sigue la lógica de la eficiencia. Ese ordenamiento (fig. 1) está dominado por la línea, por el eje. En la línea en que se sitúan, cada edificio marca una etapa del proceso de transformación del mineral. La producción impone el principio de orden que tiene la urbanización en su conjunto. Ese orden está regido por la geometría de la línea recta y el ángulo de $90^{\circ}$. Creemos que este caso ejemplifica la estética de la máquina a que aludieron los primeros racionalistas de la arquitectura moderna. La producción industrial está orientada a obtener la máxima producción con el menor esfuerzo, este es el principio de su eficiencia. Esta idea está en la base con que se concibe la organización de los edificios en la salitrera Santa Laura; fija un criterio para tomar las decisiones del proyecto. $\mathrm{Si}$ antes los asentamientos se ceñían a los cursos de agua y a las áreas cultivables, ahora, bajo el imperio de la producción industrial, el punto de partida lo establece la zona de extracción del mineral y su elaboración. Este es el nuevo axis mundus del asentamiento ${ }^{7}$.

Bajo estas consideraciones, una Oficina salitrera ${ }^{8}$ constituía una especie de claustro de producción. La vida de obreros, empleados, administradores y las familias que los siguieron estaban ordenadas a ese fin. Podemos imaginar un paralelo entre las primeras fundaciones monacales en medio del territorio culturalmente inhóspito de la Europa medieval y estos enclaves con fines y condiciones muy diferentes, pero igualmente sujetos a un rígido plan de acción para enfrentar las carencias, igualmente animados por una fuerza que pareciera sobrehumana para doblegar las limitaciones, dominar la naturaleza, alcanzar la autosuficiencia, tal vez, incluso, hasta doblegar la propia humanidad. Estas aldeas de la producción que representaron las Oficinas salitreras dieron tempranamente testimonio del zoning que caracterizará la formulación del urbanismo moderno propuesta por el IV CIAM en la Carta de Atenas (1933). En Santa Laura (cincuenta y ocho años antes) se distinguen con claridad las zonas de trabajo, esparcimiento reconocible en el pequeño triángulo donde se ubica la plaza (fig. 2) que articula el paso del área de viviendas a la zona de producción, y las vías de circulación que enlazan
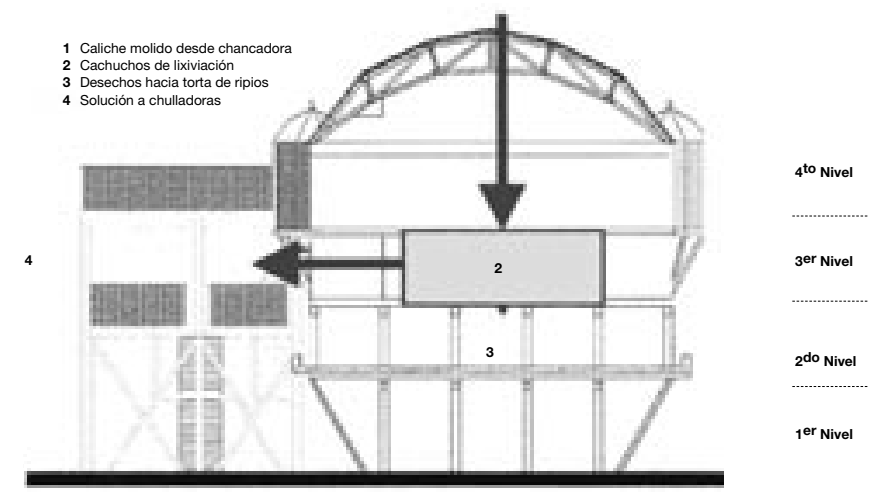

Esquema en corte de etapas de producción Fuente: Braulio Morera; El complejo de cachuchos del edificio: La Máquina como determinante del edificio y sus niveles

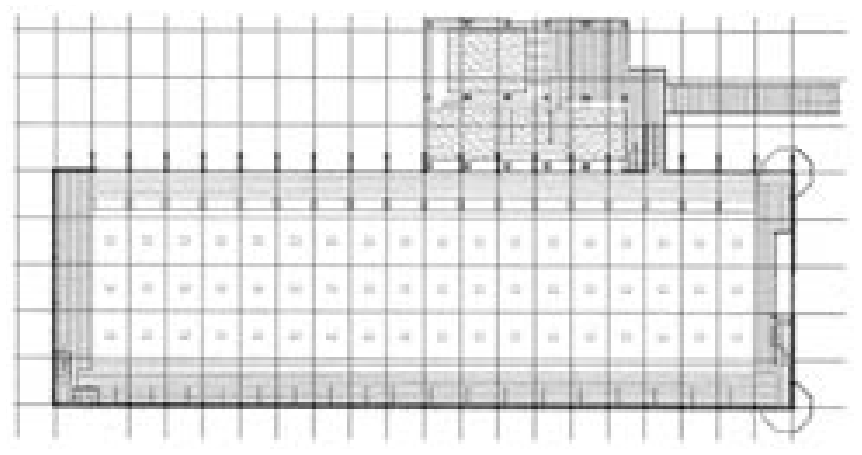

Planta nivel cachuchos Fuente: Francisca Carmona; La generatriz del edifficio industrial. La Máquina de Santa Laur

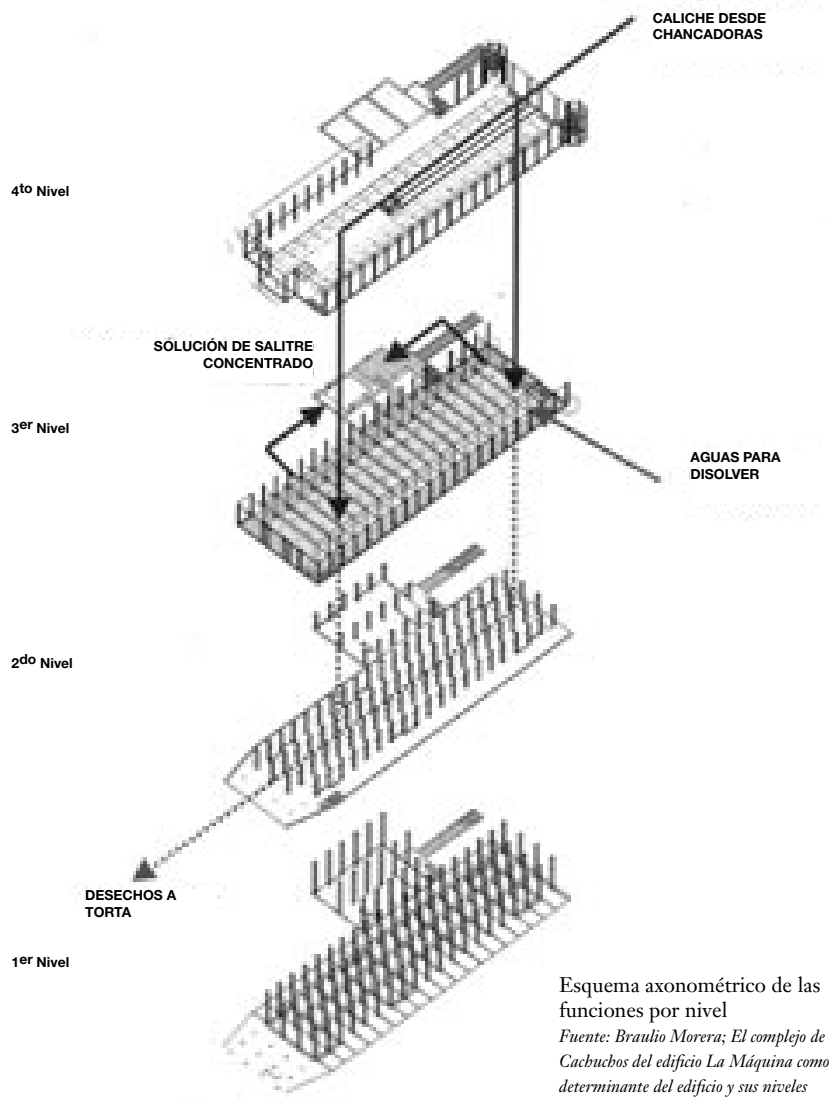


9 "La extracción del salitre (comenzaba) "us. de dinamita). (..... Dependiendo de distancia a las chancadoras, el caliche podia ser llevado en carretas tirada por mulas o por ferrocaril con carros de volcar que tenian una capaciad de 100 quintales cada uno. El proceso a manos de las "máquinas chancadoras" o "acendadoras" (los "chanchos" chancadoras podian triturar e/ materia hasta un tamaño de 1 a 2 pulgadas. lavado con agua). Al mismo tiempo se realiza el proceso de clarificación en los ese proceso). La cristalización se realiza en las llamadas "bateas" (depósitos de fierro cuyo piso está inclinado para la limpieza del material decantado). Las de secado para la última etapa de proceso". "Tomado de Carreño U El desarrollo funcional del programa como origen de una estructura orgánica. El caso del edificio de chancado de la Oficina salitrera de Santa Laural.
10 "La "máquina" se construyó en pino oregón sobre una trama rectangular de la trama se levantaron pies derechos arriostrados por diagonales, que en conjunto sostenian los "cachuchos" (Estanques donde se ejecuta el proceso de profundidad (1 pie = $=303047142 \mathrm{~m}$. Las piezas de pino oregón se unieron mediante el sistema de caja y espiga, conectores metálicos." (Tomado de Carmona A., Francisca; La Generatriz del Edificio In las diferentes zonas. Sin duda, se trata de una zonificación a ultranza, aplicada con la rigidez que la producción imponía. Se trata también de un enclave productivo, no precisamente de un ente urbano. Aquí el "ciudadano" no es propietario de nada, no es libre para iniciar actividades independientes, es un habitante asalariado. Su permanencia en la urbanización depende de la vigencia de su contrato. Su comportamiento social está regido por un protocolo laboral que impone la Compañía que explota el mineral. Aquí topan los intentos por asimilar este fenómeno al de la formación de una ciudad. Pero, a pesar de esas limitaciones, el hecho fue una experiencia cultural que debió impactar el desarrollo del país más allá de los evidentes beneficios económicos. El proceso de producción ${ }^{9}$ del salitre está constituido por un conjunto de actividades que dan origen a los principales edificios del trabajo productivo: Edificio de Chancado (fig. $3.1 \mathrm{y}$ fig. 3.2), La Máquina (fig. 4.1, fig. 4.2 y fig. 4.3) y Casa del Yodo (fig. 5.1 y fig. 5.2), definen la relación entre el área de extracción y la torta de ripio y la cancha de secado, los dos sectores donde culmina el proceso en sus dos modalidades: material de desecho y producto salitre. De estos tres edificios el más importante fue La Máquina ${ }^{10}$ donde se realizaba la transformación química del mineral en el proceso llamado lixiviación. Esta construcción ejemplifica la generación de una obra moderna como resultado de la aplicación de criterios de racionalidad: la modulación constructiva definida a partir del volumen del recipiente cachullo (fig. 6), determina la espacialidad y el dimensionamiento de la edificación. En este caso no puede ser más apropiado decir que la forma sigue a la función (fig. 7), la forma como el resto que va dejando el despliegue de la actividad, un resultado formal inesperado pero rigurosamente consecuente con el principio de acción, la función (fig. 8). Si seguimos el raciocinio que estos criterios exigen nos damos cuenta que estamos en presencia de una manera de concebir el proyecto radicalmente distinta a la que caracterizó la arquitectura de estilos. Este carácter eminentemente tecnológico, eficiente y funcional del proyecto distingue las bases de -al menos-, un modelo de proyecto arquitectónico moderno. Y no podía ser más correspondiente al carácter abstracto y ahistórico de la racionalidad de la producción industrial el concebir estas instalaciones en medio de un territorio inhóspito, una tierra estéril que rechaza la vida humana. Hay cierta complementariedad entre el modo de concebir utópico de esta modernidad y la condición inhabitable que presenta el territorio: un proyecto "sin lugar" se ejecuta en una zona "sin vida". Este juego de ideas da para pensar en una especie de "arquitectura de la negatividad" en la modernidad representada en las Oficinas salitreras.

El resto de los edificios siguen el mismo criterio en su concepción, incorporando materiales producidos industrialmente, tales como planchas de zinc, vigas y perfiles de acero, otros prefabricados como cerchas metálicas. Este panorama muestra la aplicación masiva e integral en la propuesta arquitectónica y urbana del conjunto de la Oficina salitrera con características propias de "un modo de ser la arquitectura moderna": zonificación urbana por funciones, uso de tecnologías de materiales artificiales como el acero y el hormigón armado, aplicación de elementos prefabricados como planchas de tabiquería interior y uso de materiales de medidas estandarizadas (planchas de zinc, barras de acero, madera elaborada). Y lo que fue más importante, la evidencia de un pensamiento arquitectónico regidopor los principios dela ciencia, la tecnología, la industria y la producción. ARQ

Bibliografía: Garcés, Eugenio; Las Ciudades del Salitre. Un estudio de las Oficinas Salitreras en la Región de Antofagasta. Ed. Orígenes, Santiago, 1999 ( $2^{\circ}$ ed.).
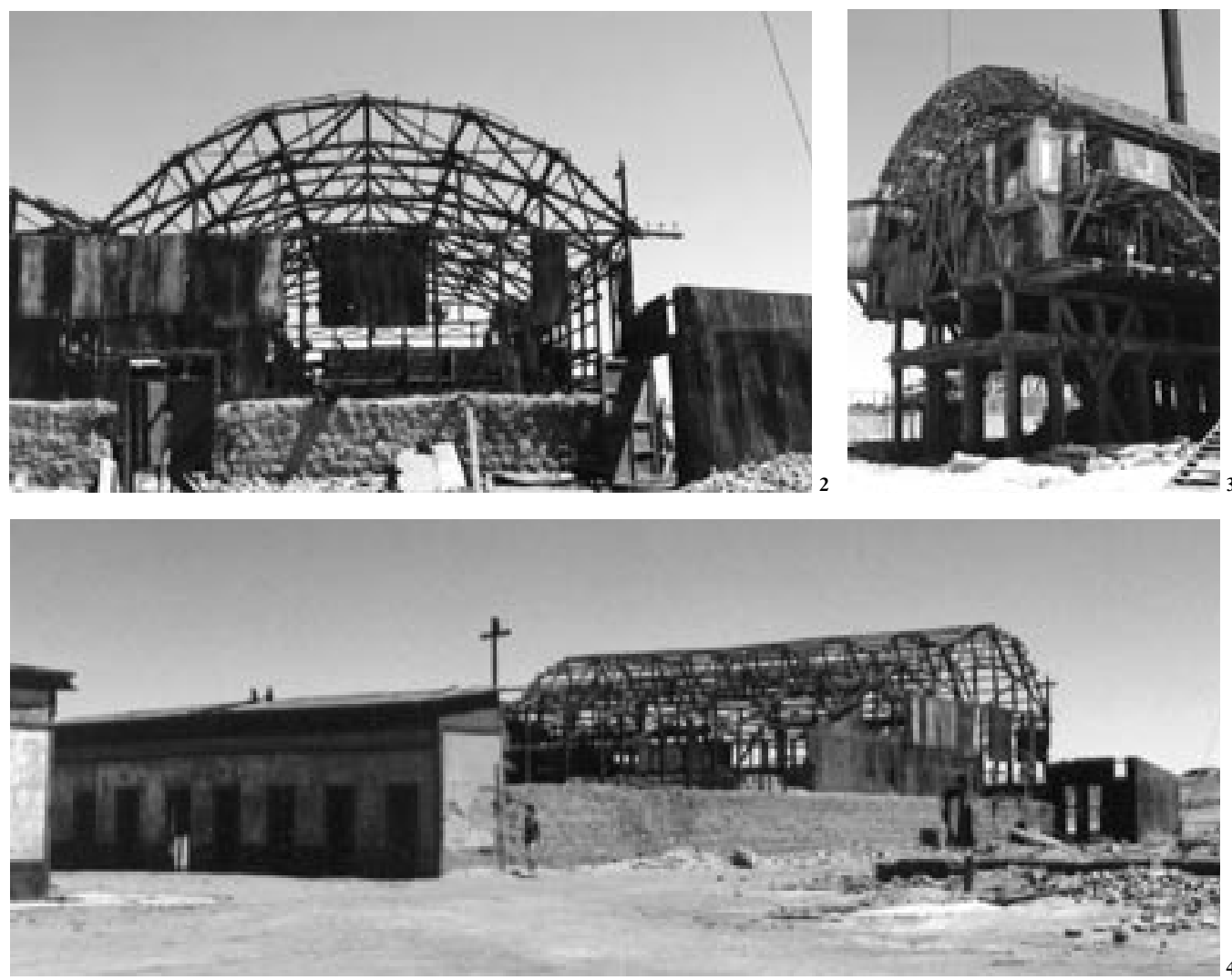

2 Casa del yodo, fachada norte
3 Edificio La Máquina
4 Casa del yodo, fachada nororiente 